\title{
A Framework for Knowledge-based Management Model on Decision-Making
}

\author{
Shao-Shin Hung ${ }^{1}$ and Damon Shing-Min Liu ${ }^{2}$ \\ Department of Computer Science and Information Engineering, \\ National Chung Cheng University \\ Chiayi, Taiwan 621, Republic of China \\ $\left\{\right.$ hss $^{1}$, damon $\left.{ }^{2}\right\} @$ cs.ccu.edu.tw
}

\begin{abstract}
Knowledge management (KM) is suggested as a method to manage and apply knowledge for business management. In this paper, we suggest a framework based on OPF (Open Process Framework) meta model for the knowledge-based decision-making. Based on the modeling method of OPF, we can translate partial and implicit knowledge resident in an individual's mental model into organized explicit knowledge. The demonstration steps of the organized knowledge model enable decision-makers to understand the structure of the target problem and identify the basic cause of it, which facilitates effective decision-making. Finally, we study knowledge management behaviors during decision making.
\end{abstract}

Keywords: Knowledge management, decision making, open process framework, open process framework

\section{Introduction}

To remain competent in the increasingly competitive global markets, enterprises must focus on a strategy to better manage the knowledge that is becoming their greatest asset. This requires organizations to provide a working infrastructure, composed of a set of knowledge-based decision making systems (KDMS) $[2,5,9,12]$, and meaningful policies for knowledge sharing. As KDMS are embedded within an organizational system they must also be designed to fit within the cultural values, authority structures and other design features of the organization. Thus KM consists of both the implementation of information systems and organizational systems with incentives, processes, and tasks to collectively generate, refine and manage organizational knowledge. The IT systems increasingly support KM we denote systems supporting $\mathrm{KM}$ as KDMS to note that an information system is only a support tool in an overall organizational KM system.

Decision making is an integral part of all managerial functions performed in an organization. It is a knowledge intensive process that demands good management of knowledge to generate a desired process outcome. During the process of managing knowledge for the purpose of decision making, a decision making unit exhibits a variety of behavioural patterns known as knowledge management behaviours. These behavioural patterns shaped by internal and external factors, affects the nature of the process outcomes. Therefore, it is crucial to understand these behaviours in order to effectively manage knowledge to generate a desired process outcome [1,8,912]. A systematic study to understand KM behaviours during decision making requires a unified framework that fully characterizes the concept of $\mathrm{KM}$, the factors shaping KM behaviours, the nature of process outcomes, and the relationships among them. Therefore, in our paper suggests a foundation for the study of KM behaviours during decision making.

The purpose of this research is not to scrutinise the nature of KM, but to suggest a method that applies this concept of KM to the business management. For this purpose, first, we will review previous research on the concept of knowledge and KM. Second, we will introduce $\mathbf{O P F}$ (Open Process Framework) Meta Model [6] as a methodology for knowledge-based decision making. It is possible to organize partial knowledge derived from the cognitive models of business- knowledge holders. Based on the above reasons, this paper presents the rationale for knowledge modeling as a foundation for successful Knowledge management System (KMS) projects and how the task of knowledge modeling can be accomplished. A method is proposed for building an effective knowledge model which can help businesses analyze and specify knowledge requirements. In addition to the knowledge creation of partial tacit into organized explicit one, it facilitate testing the impact 
of each decision alternative on the target business problem, which enables decision-makers to learn the behaviour mechanism of the target business system.

The structure of this paper is as follows. We will review previous research on the concept of knowledge model in Section of related works on the concept of knowledge model. Following that, the research assumptions, related decision making models and information processing are presented. Therefore, we explain our knowledge-based decision making system (KDMS). A real application case to a vessel company for vessel purchase decision making process will be introduced to evaluate its validity. Finally, conclusion and future research are presented.

\section{Related works on the concept of knowledge model}

A clear definition of business requirements is critical in designing a KMS. But as [5,2,11] stated that it is not apparent how that task is best accomplished. A tool — business model — with which to analyze knowledge requirements is needed. The knowledge model will help specify knowledge contents and show their flows into the business processes. A model is a simplified view of a complex reality; it is a means of creating abstraction. It enables one to better understand the domain reality $[4,6,9,10]$. This knowledge model will provide the basis for business control over requirements by identifying and describing knowledge contents and their flows around the business processes. It provides a holistic and integrated view of organizational knowledge contents. However, research studies that investigate KM behaviours generated during different types of decision making processes are limited. Another factor is decision task. The decision task that confronts the decision making unit also shape its KM behaviours. A decision task can be characterized by its structure [7] and purpose [3].

A good model will represent the domain with accuracy and completeness; it should be validated as rigorous [10,7]. According to [6,3], one of the popular meta models at the conceptual level is the $\boldsymbol{O P F}$ (Open Process Framework) Meta Model. The meta model specifies five elements of a conceptual model: work product, producers, work unit, language, and stages. The method presented in this paper is analyzed for conformity to the meta model.

According to the OPF Meta Model, the first element of a conceptual model is a work product. A work product is anything of value produced during the development process. Work products are the results of producers executing work units and are used either as input to other work units or delivered to clients [6].
Our method contains two work products. One is graphical; the other is textual. The graphical model is a Knowledge Component Diagram (KCD); the textual model is a Knowledge Catalog (KCG). KCD is the graphical representation that shows locations, flows, and relationships between decision points and knowledge components. KCG is a detailed description of knowledge component (KC). In KCG, the $\mathrm{KC}$ is decamped and described in detail. These products will be presented with more explanations in depth in the following section of the paper.

We use four constructs in the method. The first one is a decision point (DP). A DP is a node of a business process where a key decision is made. The DP is represented by an oval circle. The second notation is a rectangle. It represents the knowledge component $(\mathbf{K C})$. At every DP people will need a collection of related knowledge to make the decision. The $\mathrm{KC}$ represents the group of knowledge required to make decisions at the specific DP. The third notation is $a$ line with an arrow. The solid arrow represents a decision making process that continues as a result of the previous decision making and moves to a new DP. The dotted line with an arrow represents a decision making process that has been terminated as a result of decision making at the previous DP. Table 1 summarizes the constructs and graphical representations of the constructs.

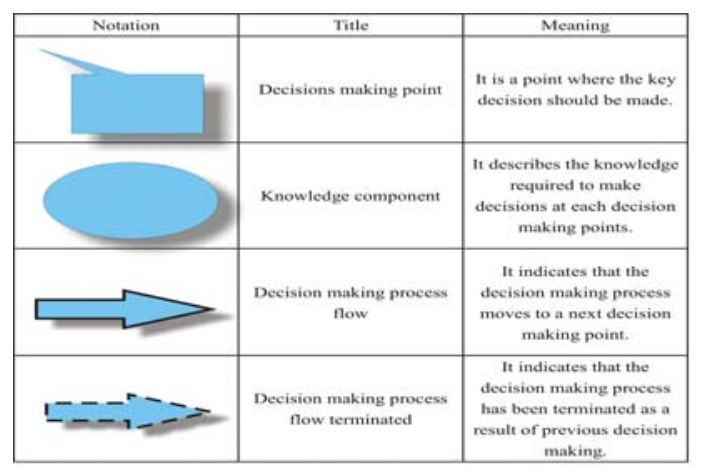

Table 1: Constructs and notations

The other elements of conceptual model are producers, work units, and stages [6]. A producer is responsible for creating, evaluating, iterating and maintaining work products. In the proposed method a producer is the knowledge modeler. Modelers must have a high knowledge of the business or access to the people with such knowledge. A work unit is a functionally cohesive operation performed by a producer. It is the activity, task or technique performed by the modeler. A stage is an identified and managed duration within a point in time at which some achievement is recognized. In our method each stage defines the work unit that should be performed during 
each stage. Stages and work units are explained in detail with examples in the next section of the paper.

\section{Real application to KDMS model}

The proposed method will be described using an example in a shipping company. The method is named knowledge-based decision making system (KDMS). KDMS consists of four stages: initiation, analysis, documentation, and evaluation. We will identify what work units are to be performed and how they are performed at each stage. As an example, a vessel purchase decision-making process of a maritime shipping company will be used. The company (SYS) is located in Singapore. It is one of the subsidiaries of a Singapore conglomerate business group. The company was established to transport bulk cements produced by its sister company (SYC). This example is not designed to accurately and completely represent the ship purchase decision-making process. Rather, it illustrates how the notations and procedures suggested can be applied to actual business processes.

\section{Stage 1: initiation}

In the first stage a business process for which we want to build a knowledge model is identified. The key business processes include purchasing vessel, scheduling vessel, making long-term cargo contracts, and managing crews. One of the most important business activities is the vessel purchase decisionmaking process, which is essentially fleet expansion. This decision is critical for several reasons. One piece of vessel in the shipping industry is a production facility; it is like a plant in other manufacturing companies. It requires a huge upfront investment. Since the ship purchase decision is one of the most critical decisions for any shipping company, very sophisticated knowledge is required for the decision. Thus the decision task force must thoroughly understand the business process: objectives, procedures, significance, etc.

\section{Stage 2: analysis}

\section{Task 1: identify key decision points}

The first task in stage 2 is to analyze key decision points (DP). After choosing a business process, the modeler reviews and analyzes it to identify key DP of the process. A business process will consist of a series of DP points where the key decisions should be made. For example, the vessel purchase decision-making process consists of several critical DP. The fundamental question is to decide whether or not to add vessel.

\section{Task 2: identify knowledge components}

The second task in Stage 2 is to analyze key knowledge components (KC) for each DP. A KC is a collection of related knowledge necessary to make a decision. The KC for key decision making at each DP must be identified. It is a description of a company's knowledge requirements for the business process chosen.

This step of identifying knowledge components involves analyzing the business process carefully. The step should not be delegated to purely technical staff or lower-level employees. The important issue is what knowledge is required in the decision-making process, not simply what we have currently. In this architecture the objective is to specify knowledge requirements, whether or not the knowledge is supplied to the company.

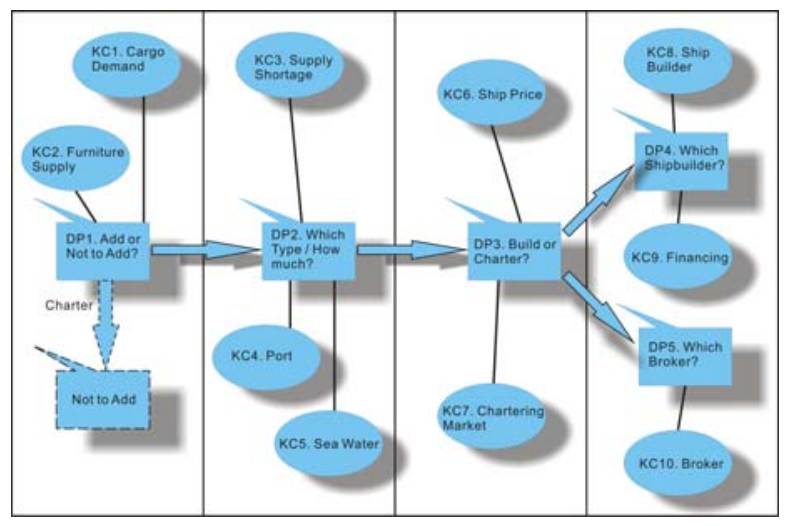

Fig. 1: Knowledge component diagram in vessel purchase decision making process

\begin{tabular}{|c|l|}
\hline Notations & \multicolumn{1}{c|}{ Meaning } \\
\hline I & $\begin{array}{l}\text { Internal Report (i.e., manuals, policies, best practices, and any } \\
\text { reports produced inside a company) }\end{array}$ \\
\hline E & $\begin{array}{l}\text { External Report (i.e., market forecast, white paper, governmental } \\
\text { statistics) }\end{array}$ \\
\hline E & $\begin{array}{l}\text { External Information System (i.e., databases, data warehouse } \\
\text { and data mining) }\end{array}$ \\
\hline I & $\begin{array}{l}\text { External Information System (i.e., suppliers' or customers' } \\
\text { system, Internet, or other commercial database) }\end{array}$ \\
\hline E & $\begin{array}{l}\text { Internal employee (i.e., employee experts' opinion, expertise or } \\
\text { experience) }\end{array}$ \\
\hline & $\begin{array}{l}\text { External expert (i.e., outside experts' expertise or solution - } \\
\text { consultants, lawyers, accountants, customers, or suppliers) }\end{array}$ \\
\hline
\end{tabular}

Table 2: Notations knowledge source.

\section{Stage 3: documentation}

\section{Task 1: knowledge component diagram}

During the third stage findings of the previous stage are documented. With DP and KC identified, we build the KCD. Together with the knowledge catalog (KCG) discussed in the next step, the KCD constitutes the knowledge architecture of an organization. A KCD shows the critical DP in the process and what 
knowledge is required for the decision making. Figure 1 is an arrangement of the findings of stage 2 analysis in graphical representation. It shows the knowledge context diagram constructed for the company's vessel procurement process.

\section{Task 2: knowledge catalog}

The second task is to document $\mathrm{KC}$ in the knowledge catalog (KCG). There are basically four types of knowledge sources. The symbols for these knowledge sources are illustrated in Table 2.

\section{Stage 4: evaluation}

Evaluating and classifying $\mathrm{KC}$ and their subcomponents are critical tasks of this stage. An example of KCG is shown in Figure 2.

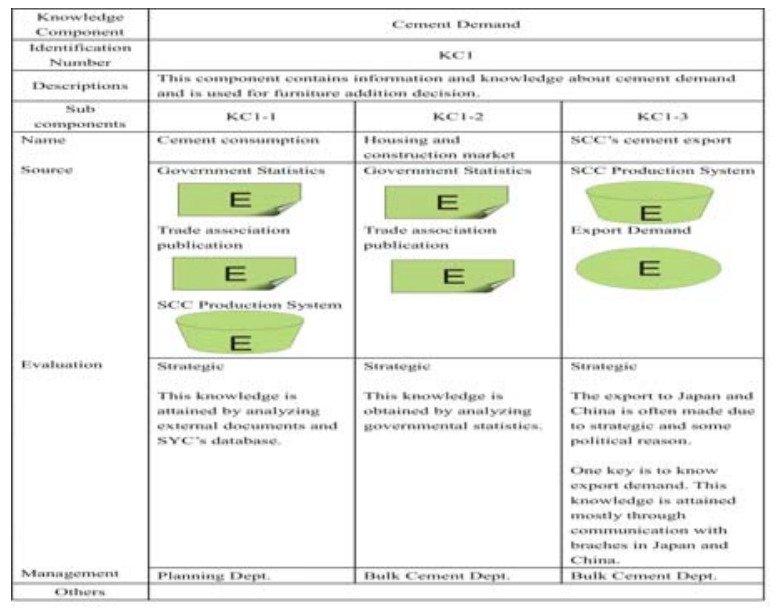

Fig. 2: Knowledge catalog.

\section{Conclusion}

Using the knowledge-based decision making system (KDMS), one can build knowledge architecture, as demonstrated through the example of the vessel purchase decision making process. We use simple notations. They can be created with any basic software. The knowledge architecture can be used as a road map to information system planning. The method, however, needs more empirical testing.

As recommended by [6,5], a modeling method can be tested by reviews via focus group, questioning by stakeholders, or real problem solving. Improvement in the method can occur as it is applied to more situations.

\section{References}

[1] C.W. Choo, The Knowing Organization, Oxford University, Oxford University Press, 1998.
[2] T.H. Davenport, and L. Prusak, Working Knowledge: How Organizations Manage What They Know. Boston, MA, Harvard Business School Press, 1998.

[3] G. DeSanctis, and R. Gallupe, “A Foundation for the Study of Group Decision Support System," Management Science, Vol. 35, No. 5, pp. 256269, 1987.

[4] H. Eriksson, and M. Penker, Business Modeling with UML: Business Patterns at Work, New York: John Wiley \& Sons, Inc., 2000.

[5] A. Gemino, and Y. Wand, "Evaluating Modeling Techniques Based on Models of Learning," Communications of ACM, Vol. 46, No. 10, pp. 79-84, 2003.

[6] B. Henderson and B. Seller, "Method Engineering for OO Systems Development," Communications of the ACM, Vol. 46, No. 10, pp. 73-78, 2003.

[7] C. Holsapple, and A. Whinston, Decision Support Systems- A Knowledge Based Approach, New York, West Publishing Company, 1996.

[8] S.K. Kim, S. Lim, and R.B. Mitchell, "Building a Knowledge Model: a Decision-Making Approach,"Journal of Knowledge Management Practice, August, Vol. 5, pp. 122-134, 2004.

[9] R. Shankar, and A. Gupta, "Towards Framework for Knowledge Management Implementation," Knowledge and Processing Management, Vol. 12, No. 4, pp. 259-277, 2005.

[10] A.M. Cook, Building Enterprise Information Architectures:Reengineering Information Systems, Upper Saddle River, New Jersey: Prentice Hall, 1996.

[11] C. Garavelli, M. Gorgoglione, and B. Scozzi, "Knowledge Management Strategy and Organization: a Perspective of Analysis," Knowledge and Processing Management, Vol. 11, No. 4, pp. 273-282, 2004.

[12] D. Amott, "Cognitive Biases and Decision Support Systems Development: a Design Science Approach,” Information Systems Journal, Vol. 16, pp. 55-78, 2006. 